\title{
Individual and Population Health: Review of Definitions and Relationships
}

\author{
Xiaoyuan Jin \\ School of Public Health, University of Minnesota, Twin Cities, USA \\ Email: Jinxx484@umn.edu
}

\begin{abstract}
There have already been many arguments about the possible relationship between individual health and population health, and many studies argue that both of these two terms are identifiable or even are hard to define if there was no informative contextualization. The opinion of this study is that they have a symbiotic relationship, which causes and influences each other. Furthermore, individual health should be the basement of the population health forever. In this article, there are three challenges facing American public health: uneven distribution of medical resources; rising healthcare cost; gun violence. The relationship between individual and population health and how to balance them are discussed and studied in the article.
\end{abstract}

Keywords: definition of public health, individual health, population (community) health, symbiotic relationship, public health challenges, balanced exercises

\section{Introduction}

When mentioning "public health", people images more about individual health care and personal health insurance Specifically, the Centers for Disease Control and Prevention (CDC) defines it as "the science and art of preventing disease, prolonging life, and promoting health through the organized efforts and informed choices of society, organizations, public and private communities, and individuals." ${ }^{[1]}$ Thus, public health, unlike at least some medical practice, aims more at optimizing and promoting "population health" rather than individual health. Oppositely, different from the healthcare work concerned with protecting the health of entire populations, there is "individual health" to focus more on each unit's health. Then, is "individual health" the complement of population health? Do these two terms have a symbiotic relationship? If yes, how should we apply the balanced practices to balance them?

From the Onyebuchi's study, there has already been the discussion that "the relationship between the individual and population health is partially built on the broad dichotomization of medicine into clinical medicine and public health". ${ }^{[2]}$ I extremely agree with this opinion. Still, I want to add more - the relationship between individual health and population health should be more dramatic, even with causal inference. Individual health goals focus on the reasons why individual health is threatened, and how to solve problems from the perspectives of individual differences and benefit, while population health goals focus on the reasons why the population health is threatened. In order to achieve a balance between individual and population health, the national medical system or institutions should re-design the care delivery system with a focus of individual differences. Only by prioritizing individual patient's needs and opening access to healthcare services first can population health be improved. On achieving the population health goal, "health promotion can prevent and delay the onset of many diseases, disability and premature death," said Shi and Signh. ${ }^{[3]}$ We should always work at both ends to reach a balance between individual and population health. In this study, it cites and discusses three challenges facing public health recently: 1) uneven distribution of medical resources; 2) rising healthcare; 3) gun violence. The artivle uses these topics to discuss the relationship between individual and population health specifically.

\section{Uneven distribution of medical resources}

Inadequate medical resources and uneven distribution of resources are major problems that plague the entire healthcare industry. According to a report published in the Modern Concern of The Journal of Health Affairs, the inequality of Americans' access to health care has increased in recent years. ${ }^{[3,4]}$ Currently, the rich occupy most of the medical resources in the United States, and they are in significantly better health than the rest of the population. The data shows that between 2004 and 2012, as growth in national health spending slowed, the share of health-care resources consumed by the fifth richest of Americans grew by 19 percent. ${ }^{[5]} 7 \%, 57 \%$ faster than the rate at which the middle class consumes health care resources; During that time, the share of health care consumed by the poorest fifth of Americans fell, by 
three percentage points $7 \% \cdot{ }^{[5]}$ Another unequal distribution implies that many areas have relative primary-care shortages, especially in rural communities and areas with measurable social deprivation. ${ }^{[2,4]}$ The data shows that there are about 80 primary care physicians per 100,000 people in the United States; however, the average is only about 68 per 100,000 physicians in rural areas and 84 per 100,000 physicians in urban areas. ${ }^{[6]}$ Although the uneven distribution of medical resources directly leads to inability to receive medical assistance for most people, which fundamentally poses a threat to public health, the real issue lies on inequity that certain individuals are unable to access health services and assess their needs.

When meeting this challenge, I believe we can balance individual and population health by integrating social factors and individual status. The design of the health care system should include resources and services supporting individual differences and addressing the social factors, particularly in disease diagnosis, treatment and prevention. For example, Health Leads is an organization that integrate and align resources for patients to address their social needs and help them stay healthy. It provides patients with community resources and public assistance to meet their basic needs such as food and shelter, therefore providing the people with low income a safe place to recover from acute injury or illness. ${ }^{[15,17]}$ In 2014, Health Leads served more than 13,000 low-income patients in seven cities. ${ }^{[15,17]}$ Promoting the individual' health can protect the population health, same with the herd immunity principle that population health benefit from ensuring individual health.

\section{Rising healthcare cost}

The current U.S. Healthcare system leaves many people without the ability to pay for the health care they need. As more individuals struggle to extend their lifespan and live a healthier and higher-quality life, their concerns increase as the healthcare costs increases too. ${ }^{[1,5]}$ Studies reveal that costs for healthcare and expenditure frequently grow at rates that exceed the inflation rate, and healthcare costs are anticipated to rise intensely in the future ${ }^{[6]}$ The Society for Human Resource Management states that, the Office of the Actuary at the Centers for Medicare and Medicaid Services has estimated that the general care expenditure in America may rise at an average rate of about 5.8 percent yearly from year 2015 through year 2025, reaching 1.3 percent more than the predicted yearly rise in the general GDP ${ }^{[1]}$ The rising health care cost takes up greater portions of the total economic output. Because economic resources are limited, the rising health care costs means that Americans must forgo other goods and services when most of their income is spent on health care. ${ }^{[5]}$ Based on the different socioeconomic status, individuals' life and health quality may be negatively impacted afterwards.

Similarly, with the rising overall healthcare costs, healthcare system should check the individual health care costs, and then analyze the macro level of financial management from health care system. As Donald suggests, the first step for a systematic approach to cost control should be defining, measuring, and clarifying the per capita cost of medical care for a defined population, and then work on health promotion to check the whole population management. ${ }^{[14]}$ For example, companies can indicate on employees' paychecks the amount of money spent on health insurance provided by the company. The Centers for Medicare and Medicaid Services can provide regions with cost information per beneficiary to allow comparisons of costs and inflation across the country. ${ }^{[3,17]}$

\section{Gun violence}

Gun violence is one of the main social concerns in the American society. The United States has 120.5 guns per 100 people, or about $393,347,000$ guns overall, which is the highest per capita and total number in the world. ${ }^{12}$ As reported, every day, 100 Americans are killed with guns and hundreds more are shot and injured. By contrast, robberies involving guns are three times more likely to result in death than robberies using other weapons. ${ }^{[13,14]}$ Also, having access to a gun increases the risk of death by suicide by three times, and nearly two third of gun deaths are suicides ${ }^{[13]}$ The effects of gun violence extend far beyond these casualties-gun violence shapes the lives of each American individual who witnesses it, knows someone who was shot, or lives in fear of the next shooting. In this light, gun violence is now a major threat to social health in the American society.

When applying this balanced act on solving gun violence, based on Shi and Singh's advice, we should "provide health education" to individuals to "understand the determinants of health", "utilize community health assessment" from populations, and "promote national initiatives" to build outreaches and to keep population healthy. ${ }^{[3]}$ For example, The Healthy People 2020 not only educates invigorating communities through greening vacant lots, which is associated with a significant reduction in gun assaults to individuals, but also reports and expresses the gun violence data details of the community to people. Furthermore, this website resource promotes the organization Pennsylvania Horticultural Society to 
provide gun violence preventions to whole population. ${ }^{[14]}$

\section{Conclusion}

Public health is a complex study, which concerns the management with the individual and the community. However, we can use the relationship between individuals and the population to work and practice. As the discussion about the relationship between the individual and population health in this study, working on individual health is the basement to explore and enlarge the efficiencies of improving the population health. Therefore, the force on personal hygiene is beneficial for population health management. This finding also will be the purpose of seeking the relationship between individual and population health.

\section{References}

[1] Centers for Disease Control and Prevention. Introduction to Public Health. Public Health 101 Series. 2018.

[2] Onyebuchi A. Arah. On the relationship between individual and population health. Med Health Care and Philos. 2009. DOI 10.1007/s11019-008-9173-8.

[3] Leiyu Shi, Douglas A. Singh. Delivering Health Care in America: A Systems Approach, 7th edition. Burlington. MA: Jones and Bartlett Learning. 2019. ISBN: 9781284124491.

[4] Hilary B, Michael RR, Matthew DM, Grant M. Rural And Nonrural Primary Care Physician Practices Increasingly Reply On Nurse Practitioners. Health Affairs. 2018; 37(6). https://www-healthaffairs-org.ezp3.lib.umn.edu/ doi/10.1377/hlthaff.2017.1158.

[5] Briggs A, Sculpher M, and Buxton M. Uncertainty in the economic evaluation of health care technologies: the role of sensitivity analysis. Health Econ.2014; 3(2): 95-104. https://www.ncbi.nlm.nih.gov/pubmed/8044216. Accessed MarApr, 2014.

[6] Rural and Urban Health. Health Policy Institute. https://hpi.georgetown.edu/rural/.

[7] Why Are Americans Paying More For Healthcare? Peterson Foundation.org. https://www.pgpf.org/blog/2019/03/whyare-americans-paying-more-for-healthcare. Accessed March 15, 2019.

[8] Daniel Waldo. National Health Accounts: A Framework For Understanding Health Care Financing. Health Affairs. 2018; 37(3). https://www-healthaffairs-org.ezp1.lib.umn.edu/doi/10.1377/hlthaff.2017.1629.

[9] Five top challenges affecting healthcare leaders in the future. Becker's Hospital Review. https://www. beckershospitalreview.com/hospital-management-administration/five-top-challenges-affecting-healthcare-leaders-inthe-future.html. Accessed February 13, 2018.

[10] Should More Gun Control Laws Be Enacted? ProCon.org. https://gun-control.procon.org/. Last updated on May 2, 2019.

[11] Gun Violence in America. EveryTown for Gun Safety.org. https://everytownresearch.org/gun-violence-america/. Accessed April 4, 2019.

[12] Jens L, Philip JC. The Benefits of Reducing Gun Violence: Evidence from Contingent- Valuation Survey Data. Journal of Risk and Uncertainty. 2001; 22(3): 207-226. https://link.springer.com/article/10.1023/A:1011144500928.

[13] David K. Beyond The Triple Aim: Integrating The Nonmedical Sectors. Health Affairs. 2008; 10: 1377. https://www. healthaffairs.org/do/10.1377/hblog20080519.000393/full/.

[14] Donald MB, Thomas WN, John W. The Triple Aim: Care, Health, And Cost. Health Affairs. 2008; 27(3). https://www. healthaffairs.org/doi/full/10.1377/hlthaff.27.3.759.

[15] What We Do. Health Leads org. https://healthleadsusa.org/what-we-do/.

[16] Reducing Violent Crime and Invigorating Communities Through Greening Vacant Lots. HealthyPeople.gov. https:// www.healthypeople.gov/2020/healthy-people-in-action/story/reducing-violent-crime-and-invigorating-communitiesthrough-greening-vacant-lots. Accessed February 22, 2012.

[17] Care and Payment Models to Achieve the Triple Aim. American Hospital Association (AHA) org. https://www.aha. org/ahahret-guides/2016-01-26-care-and-payment-models-achieve-triple-aim-0. Accessed 2015. 